\section{Relationships between the Religious Backgrounds and Evolution Acceptance of Black and Hispanic Biology Students}

\author{
M. Elizabeth Barnes, ${ }^{\dagger}$ K. Supriya, ${ }^{\ddagger}$ Hayley M. Dunlop, ${ }^{\ddagger}$ Taija M. Hendrix, ${ }^{\ddagger}$ \\ Gale M. Sinatra, and Sara E. Brownell** \\ ${ }^{\dagger}$ Department of Biology, Middle Tennessee State University, Murfreesboro, TN 37132; ; Biology \\ Education Research Lab, Research for Inclusive STEM Education Center, School of Life Sciences, \\ Arizona State University, Tempe, AZ 85287; and ${ }^{\S}$ Rossier School of Education, University of \\ Southern California, Los Angeles, CA 90089
}

\begin{abstract}
The evolution education experiences of students of color represent an emerging area of research, because past inquiries indicate these students have differential outcomes, such as lower evolution acceptance and severe underrepresentation in evolutionary biology. Religion is often an important support for students of color who are navigating a science, technology, engineering, and mathematics culture that privileges White nonreligious students. For instance, religion helps mitigate the negative effects of racism, but religious students are also more likely to experience conflict when learning evolution. In this nationwide study, we examined the extent to which strong religiosity among students of color can explain their lower evolution acceptance. We surveyed students in 77 college biology courses across 17 states and found that Black/African American students tend to be more religious and less accepting of evolution than any other racial/ethnic identity group and that Hispanic students tend to be slightly more religious and slightly less accepting of evolution than White students. Importantly, we find that religious background is an important factor associated with Black and Hispanic students' lower levels of evolution acceptance. This study suggests that the biology community should become more inclusive of Christian religious students if it wishes to foster inclusive evolution education for Black and Hispanic students.
\end{abstract}

\section{INTRODUCTION}

Students of Color Have Differential Evolution Education Outcomes

Students of color possess unique cultural wealth for persisting in the face of adversity (Yosso, 2005), but a breadth of research documents that these students still face many disadvantages in science, technology, engineering, and mathematics (STEM) education (Hurtado et al., 2007; Holdren et al., 2010). Emerging research suggests that, specifically, the evolution education experiences of students of color may differ from those of White students (Graves, 2019). Several recent studies have found that biology students of color, on average, accept evolution less (Metzger et al., 2018; Sbeglia and Nehm, 2018), understand evolution less (Mead et al., 2015), and may feel a diminished sense of belonging in evolutionary biology (O’Brien et al., 2020). Further, Black/African American, ${ }^{1}$

\footnotetext{
${ }^{1}$ In this article, we choose to use the term "Black/African American," because our study population identified as Black/African American on our surveys and the term is more inclusive than "Black" or "African American" alone; not all those who identify as Black have recent African ancestry and not all who identify as Black in our classrooms consider themselves American. However, researchers use different terms, such as just "Black" or just "African American" to describe individuals, so when referring to other studies/data, we use the terminology of the authors of those studies/data.
}

Elisabeth Schussler, Monitoring Editor Submitted Oct 15, 2019; Revised Sep 16, 2020; Accepted Oct 8, 2020

CBE Life Sci Educ December 1, 2020 19:ar59 DOI:10.1187/cbe.19-10-0197

*Address correspondence to: Sara E. Brownell (sara.brownell(aasu.edu).

(c) 2020 M. E. Barnes et al. CBE-Life Sciences Education @ 2020 The American Society for Cell Biology. This article is distributed by The American Society for Cell Biology under license from the author(s). It is available to the public under an Attribution-Noncommercial-Share Alike 3.0 Unported Creative Commons License (http://creativecommons.org/licenses/ by-nc-sa/3.0).

"ASCB®" and "The American Society for Cell Biology ${ }^{\circledR}$ " are registered trademarks of The American Society for Cell Biology. 
Hispanic, ${ }^{2}$ and Native American students, on average, experience lower gains in acceptance of evolution after evolution instruction compared with White or Asian students (Sbeglia and Nehm, 2018). Given that evolution is a foundational component of biology education (American Association for the Advancement in Science, 2011), these experiences may contribute to the underrepresentation of these groups in biology (Mead et al., 2015; Salazar et al., 2019). So why do students struggle with accepting evolution or feeling a sense of belonging within evolutionary biology? One potential explanation is that students struggle with a perceived conflict with their religious beliefs when learning evolution (Barnes et al., 2017a,b, 2020b; Barnes and Brownell, 2017, 2018; Truong et al., 2018).

\section{The High Proportion of Religious Christians among Black and Hispanic Students May Explain Their Levels of Evolution Acceptance}

Both Black/African American and Hispanic individuals are more likely to identify as Christian (Pew, 2009c), and Christians are more likely to reject evolution (Pew, 2009a; Gallup, 2019). Black/African American and Hispanic individuals, on average, also report higher levels of commitment to a religion (religiosity), which is one of the strongest factors associated with lower acceptance of evolution (Glaze et al., 2014; Dunk et al., 2017; Barnes et al., 2019). Further, religious biology students can feel as if they do not fit in with the secular culture of biology, experience negative remarks about religion from their professors and peers, and feel as though revealing their religious identity would be a disadvantage to them if they were to pursue a career in biology (Barnes et al., 2017b; Barnes and Brownell, 2018). Christian college students perceive that there is a negative stereotype about the abilities of Christians in science and even experience stereotype threat on assessments that they are told measure their scientific ability (Rios et al., 2015). Thus, the higher proportion of strong religious backgrounds among Black/African American and Hispanic students may explain in part the differential evolution perceptions researchers have documented between students of color and White students (Mead et al., 2015; Metzger et al., 2018; Sbeglia and Nehm, 2018; Salazar et al., 2019; O'Brien et al., 2020). This would suggest, that in order to be inclusive of many students of color, evolution educators would need to be inclusive of Christians. However, a complication in thinking about race/ethnicity ${ }^{3}$

\footnotetext{
${ }^{2}$ In this article, we choose to use the term "Hispanic" to capture this ethnicity, because our study population identified as Hispanic on our survey. However, researchers use different terms such as "Latino," "Latina," "Latin@," and "Latinx" that may be more inclusive of individuals who are of Latin American origin but are not descended from native Spanish speakers, so when referring to other studies/ data, we use the terminology of the authors of those studies/data.

${ }^{3}$ In defining race, we adopt the definition of the American Association of Physical Anthropology (AAPA): "Race does not provide an accurate representation of human biological variation. It was never accurate in the past, and it remains inaccurate when referencing contemporary human populations. Humans are not divided biologically into distinct continental types or racial genetic clusters. Instead, the Western concept of race must be understood as a classification system that emerged from, and in support of, European colonialism, oppression, and discrimination. It thus does not have its roots in biological reality, but in policies of discrimination. Because of that, over the last five centuries, race has become a social reality that structures societies and how we experience the world. In this regard, race is real, as is racism, and both have real biological consequences" (AAPA, 2019). In line with this definition, we refer to "race" throughout this article as a social identity (which often has negative consequences for an individual's experiences due to racism) and not a biological classification.
}

and Christian identity is that, among students of color, certain racial/ethnic groups, on average, tend to have Christian affiliations that could be perceived as more compatible with evolution and the culture of biology than other Christian affiliations.

\section{Hispanic Individuals, on Average, Tend to Identify as Catholic}

The most prevalent religious affiliation of Latinx individuals is Catholicism (Pew, 2015). Catholic individuals are underrepresented in science, but are less underrepresented than other Christian groups. Twenty-four percent of the American public identifies as Catholic, while only $10 \%$ of scientists report this affiliation (Pew, 2009c). However, 28\% of the public identifies as evangelical Protestant and only $4 \%$ of scientists identify as evangelical Protestant (Pew, 2009c, 2015). Forty-eight percent of Latinx individuals are Catholic, and 19\% are evangelical Protestant (Pew, 2015). Because Catholic individuals tend to be more accepting of evolution compared with evangelical Protestant individuals (Gallup, 2019), it may be that, on average, Hispanic students do not struggle to accept evolution as much as Black/African American students who identify more closely with evangelical Protestant Christian affiliations.

\section{Black/African Americans, on Average, Have Strong Protes- tant Christian Backgrounds and Beliefs}

Seventy-eight percent of African Americans identify as Protestant, and 59\% belong specifically to historically Black Protestant churches (Pew, 2009b). Among the general U.S. population, Black/African Americans score higher on religiosity measures than any other racial/ethnic group, including Hispanic individuals. Eighty-one percent of African American individuals said that they are "very certain" about their belief in God compared with $61 \%$ of White individuals and $59 \%$ of Hispanic/Latino individuals (Pew, 2015). Further, 75\% of African American individuals said that religion is an important part of their lives compared with $49 \%$ of White individuals and 59\% of Hispanic/ Latino individuals (Pew, 2015).

Research indicates that the importance of religion in Black/ African American culture extends to Black/African American college students. African American college students at elite universities are more likely to attend religious services at least once per week and to report that they are more observant of their religion compared with White and Hispanic/Latino students (Mooney, 2010). Therefore, it is likely that Black/African American students in college biology classes tend to be more religious compared with students with other racial/ethnic identities and thus may accept evolution less than students from other racial/ethnic groups (Mead et al., 2015; Salazar et al., 2019; O'Brien et al., 2020). Indeed, Mead et al. (2015), found that Black/African Americans in the biology community at two STEM conferences for students of color reported being more religious than those from other racial/ethnic groups.

\section{Intersectionality of Racism and Secularism May Exacerbate Negative Evolution Education Outcomes}

Critiques of single-axis frameworks in activism and theory have a long history, particularly among Black feminists, including but not limited to Sojourner Truth (1851), bell hooks (1981), Audre Lorde (1984), Patricia Hill Collins (1986), Angela Davis (1983), and the Combahee River Collective (1983). The term 
"intersectionality" was originally coined by Kimberlé Crenshaw to describe the complexity of discrimination experienced by Black women due to the interlocking systems of oppression of racism and sexism that cannot be adequately described using single-axis frameworks (Crenshaw, 1989; Collins, 1990) and has since been used to describe the experiences of women of color in STEM (Morton and Parsons, 2018). In our study, the interlocking systems of oppression would be racism and secularism in academic biology. If a student identifies as Black/African American and/or Hispanic and Christian, they will experience discrimination based on at least two axes of oppression in science. Similar to Crenshaw's analysis of race and gender intersectionality, it may be the case that being both a student of color and a Christian may create extra and/or unique barriers to success in STEM compared with only holding a Christian identity or identifying as a person of color. Thinking about the intersection of racial/ethnic identity and Christian identity both in evolution education and STEM retention studies could help instructors better understand how to support students of color (Dunk et al., 2019). In this study, we examined whether being both religious and Black/Hispanic would predict lower evolution acceptance than being religious and White.

\section{Situating the Current Study}

High levels of religiosity among students of color may be associated with differences in their levels of evolution acceptance, but past studies have not been able to fully explore this relationship (Bailey et al., 2011; Mead et al., 2015; O'Brien et al., 2020). To our knowledge, no studies have explored potential intersectionality between race/ethnicity and religiosity with respect to evolution acceptance. In this study, we explore whether there is a negative compounding effect of race/ethnicity and religiosity on students' evolution acceptance. Further, past studies have not been able to evaluate the role of religiosity as a mediator of Black/African American, Hispanic, Asian, and White student evolution acceptance. In this study, we aimed to evaluate how religiosity might be associated with different levels of evolution acceptance among undergraduate biology students of color with different racial/ethnic identities.

We also disaggregate students of color to explore their evolution acceptance separately. Students of color are often analyzed as a single group in biology education studies because of the small numbers of these students in study samples (i.e., Eddy et al., 2015; Jordt et al., 2017; Cooper et al., 2018; Metzger et al., 2018; Rodriguez et al., 2018; Sbeglia and Nehm, 2018; Ballen et al., 2019; Estrada et al., 2019; Meaders et al., 2019). ${ }^{4}$ The frequent argument for grouping them is that, although these individuals have different experiences based on their respective races/ethnicities, they share a common experience of being marginalized and underrepresented in institutions of higher education based on their race/ethnicity. However, Black/ African American, Hispanic/Latinx, Native American/Alaskan Native, Native Hawaiian/Pacific Islander, and Asian people have vastly different histories and experiences of racial discrimination in the United States. Lumping these groups together may be

${ }^{4}$ In these studies, Asian students are sometimes included as a group in analyses with students of color, sometimes included with White students, sometimes considered separately from other groups, and sometimes are not included in the analyses at all. particularly inappropriate for evolution education studies. Among people of color, Americans with different racial/ethnic identities have different levels of support for the teaching of evolution (Salazar et al., 2019), and STEM students with different racial/ethnic identities have different levels of a sense of belonging within evolutionary biology (O'Brien et al., 2020). Thus, conclusions made about these students' acceptance of evolution from past studies that have aggregated all of them into a single group in their analyses (Metzger et al., 2018; Sbeglia and Nehm, 2018) could lead to inaccurate interpretations about the acceptance of evolution of students from different racial/ethnic backgrounds. For instance, we may assume Hispanic and Black/African American biology students have equally lower evolution acceptance rates when only one group experiences lower evolution acceptance. In this study, we aimed to collect data from a large enough number of biology students to be able to disaggregate Black/African American, Hispanic, Asian, and White students' evolution acceptance.

Finally, we test both a mediation model and a moderation model to see whether differences between the religious background of groups are associated with the differences in evolution acceptance between groups and whether these mediations are weaker or stronger for different religious backgrounds.

\section{RESEARCH QUESTIONS}

1. On average, are Black/African American, Hispanic, Asian, and White undergraduate biology students' levels of religiosity and acceptance of evolution statistically different?

2. Is there a compounding negative association of race/ethnicity and religion on students' evolution acceptance? In other words, are Black/African American or Hispanic students who are religious less accepting of evolution than White students who are religious?

3. Are the differences in evolution acceptance between students with different race/ethnicities (Black/African American and White; Hispanic and White) associated with their differing levels of religiosity?

\section{METHODS}

We identified instructors of biology courses through their institutional profiles and also recruited instructors via the Society for the Advancement of Biology Education Research Listserv. To maximize the sample size of Hispanic and Black/African American students for statistical analyses, we wanted to recruit instructors from minority-serving institutions and large-enrollment institutions in the United States where greater than $5 \%$ of the student population identifies as Hispanic or Black/African American. We used the directory of biology faculty from each of the institutions that met these criteria, and if the "courses taught" listed on the instructor's profile included introductory biology, the instructor's name, email, and institution were recorded in a spreadsheet. Many websites did not explicitly state which courses instructors taught, and in these cases their names and emails were recorded. We emailed these instructors and asked them if they would be willing to send out a link to a Qualtrics survey to the students in their class and offer a small amount of extra credit for completing the survey. All activities were approved by Arizona State University's Institutional Review Board protocols nos. 8191 and 3910. 
We collected data on student racial/ethnic identities and their religiosity, religious affiliations, and acceptance of evolution from 9856 students across 77 biology courses that were offered from Fall 2017 to Spring 2019 across 17 different states. The survey was open for $\sim 1-2$ weeks for each data collection to give students enough time to complete it.

\section{Measures}

We asked students to self-identify from the following list of racial/ethnic identities: (1) American Indian, Native American, or Alaskan Native, (2) Asian, (3) Black/African American, (4) Native Hawaiian or Other Pacific Islander, (5) Hispanic (6) White, (7) other not listed, and (8) prefer not to answer. Students were instructed that they could check more than one box if they held multiple identities. We also asked students to self-identify from the following list of religious affiliations: agnostic, atheist, Buddhist, Christian-Catholic, Christian-The Church of Jesus Christ of Latter Day Saints, Christian-Protestant, Christian-other, Christian-nondenominational, Hindu, Jewish, Muslim, nothing in particular, other faith, and decline to state. We also asked students to report their gender, age and their parents' highest level of education to control for potentially confounding demographic factors, because gender, age, and parents' level of education are sometimes related to evolution education outcomes (Bailey et al., 2011; Baker, 2013; Rissler et al., 2014; Sbeglia and Nehm, 2018).

To measure acceptance of evolution, we used the previously published Inventory of Student Evolution Acceptance (I-SEA), which includes 24 statements with which students agree or disagree on a five-point scale. The I-SEA measures acceptance of microevolution (e.g., "natural selection is a reasonable explanation that describes the ways in which groups of organisms have changed over time"), acceptance of macroevolution (e.g., "I think that new species arise from ancestral species"), and acceptance of human evolution (e.g., "like other organisms, the human species is a result of evolution from an ancestral group"). We chose to use the I-SEA instead of other published instruments such as the Measure of Acceptance of the Theory of Evolution or the Generalized Acceptance of Evolution Evaluation (Rutledge and Warden, 1999; Smith et al., 2016), because the I-SEA is the only instrument that disaggregates student acceptance of microevolution, macroevolution, and human evolution, each of which has been shown to be a different construct (Nadelson and Southerland, 2012; Sbeglia and Nehm, 2019). Further, the I-SEA addresses many limitations of other acceptance of evolution measurement tools (Barnes et al., 2019; Sbeglia and Nehm, 2019). The reliability of each scale in this study was high (microevolution acceptance: $\alpha=0.87$; macroevolution acceptance: $\alpha=0.87$; human evolution acceptance: $\alpha$ $=0.92$ ).

We used four items from a previously published instrument used in the psychology of religion to measure student religiosity (Cohen et al., 2008). The items measure the intrinsic strength of one's religious identity (e.g., "I consider myself a religious person") and participation in religious activities (e.g., "I attend religious services regularly") and are similar to other common measures used both in studies of religion (Dingemans and Van Ingen, 2015; Ecklund et al., 2018) and studies of evolution acceptance (Rissler et al., 2014; Dunk et al., 2017). The instrument consisted of four items with which the students agree or disagree on a five-point scale. A higher number on the scale indicates higher religiosity. The reliability of the scale in this study was high $(\alpha=0.91)$.

\section{Analyses}

We used R v. 3.6.2 for all analyses (R Core Team, 2019).

Following the recommendation from Sbeglia and Nehm (2018), we converted I-SEA Likert responses into linear interval scale measures (Linacre and Wright, 1993; Boone, 2016) by running three unidimensional Rasch models (acceptance of microevolution, macroevolution, and human evolution). We also converted religiosity Likert responses into linear interval scale measures by running a unidimensional Rasch model. For all Rasch models, we modified the Likert scale coding to start at zero (i.e., $0=$ strongly disagree to $4=$ strongly agree, instead of 1-5). We ran polytomous partial-credit Rasch models (Robitzsch et al., 2018) and used a weighted maximum-likelihood estimation (WLE) in the R package TAM to calculate theta values, that is, person measures using the function tam.wle. These person measures were used as the measures of acceptance of microevolution, macroevolution, human evolution, and religiosity in the rest of the analyses (see Supplemental Figures 1-4 for Wright maps). We examined the eigenvalues of the residuals for each Rasch model to check that a unidimensional model is a good fit for the data. We assessed item fit using the msq.itemfit function, which computes weighted mean squares infit and outfit statistics based on weighted likelihood estimates. Finally, we examined the expected a posteriori/plausible value reliability index (EAP/PV), a measure of item reliability, and the WLE person separation index, a measure of person reliability that estimates whether a similar order of person abilities would be generated by items of similar difficulty.

To ensure that we had at least 25 students at each intersection of race/ethnicity and religion for statistical analyses (see Supplemental Table 1), we divided students into four racial/ ethnic groups ${ }^{5}$ (Black/African American, Asian, Hispanic, or White) and four religious affiliations (Christian-Catholic, non-Catholic Christian, no affiliation [atheist, agnostic, or nothing in particular], and other faith [Hindu, Buddhist, Muslim, Jewish, or other faith]).

To examine how student religiosity and evolution acceptance vary by race/ethnicity, we used linear mixed models (LMMs) with course as a random effect; race/ethnicity as a predictor; and religiosity, microevolution acceptance, macroevolution acceptance, and human evolution acceptance as response variables using the $\mathrm{R}$ package nlme (Pinheiro et al., 2014). We dummy coded all categorical variables for all the analyses with the following reference levels: gender: female; race/ethnicity: White; religious affiliation: no religious affiliation; parent education: less than high school; region: West. We calculated estimated marginal means of slopes of the relationship between religiosity and evolution acceptance and did pairwise comparisons with the $p$ values adjusted for multiple testing using the

\footnotetext{
${ }^{5}$ There were racial/ethnic identities that were not prevalent enough for analyses. We coded students who checked "American Indian," "Native American," "Alaskan Native," "Native Hawaiian," "Other Pacific Islander," and "other not listed," as "other race/ethnicities." We also included "multiracial" students in this category, because their experiences are likely to be different from students who exclusively checked one box for their racial/ethnic identity. The results from these students are not included in the analyses presented in the main text of the article.
} 
a

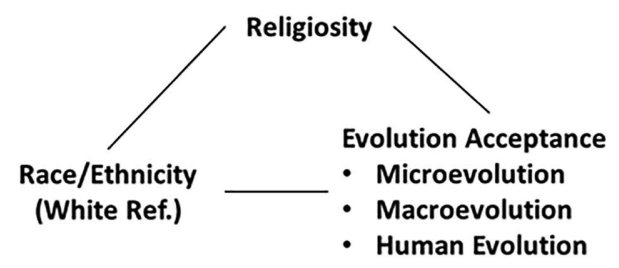

b

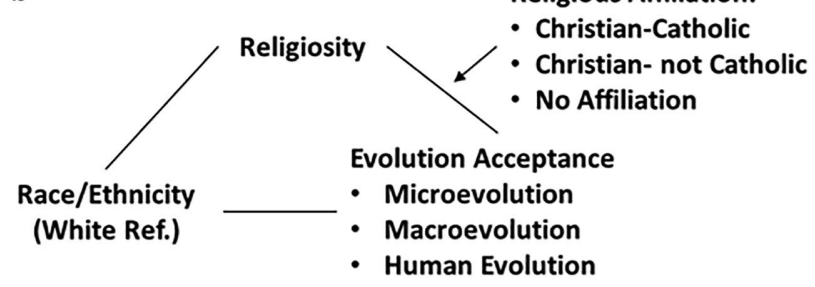

FIGURE 1. (a) Simple mediation model with religiosity as the mediator for the relationship between race/ethnicity and evolution acceptance. (b) Moderated mediation model with religiosity as the mediator and religious affiliation as the moderator. These figures do not include the random effects and covariates that are included in our statistical analyses.

Tukey method to determine significant differences between groups in the R package emmeans (Lenth et al., 2018). We converted religiosity and age to z-scores before the analyses so that the resulting regression coefficients are standardized.

We examined whether there was a compounding negative effect of identifying as Black/African American, Hispanic, or Asian at higher religiosity levels on evolution acceptance. Thus, we examined whether identifying as either Black, Hispanic, or Asian at higher religiosity levels resulted in lower evolution acceptance compared with identifying as White at higher religiosity levels. We did a similar analysis using religious affiliation in place of religiosity (Catholic, non-Catholic Christian, and no affiliation) to assess whether there is a compounding negative effect of race/ethnicity and religious affiliation on acceptance of evolution. We again used LMMs to examine acceptance of microevolution, macroevolution, and human evolution as the response variable, with course as a random effect (varying intercepts). In these models, we included covariates (religious affiliation, age, gender, parent education [five levels], and region [seven levels]) and an interaction between race/ethnicity and religiosity or affiliation as the predictors. We calculated estimated marginal means and did pairwise comparisons with the $p$ values adjusted for multiple testing using the Tukey method to determine significant differences between groups.

Finally, to see whether differences in levels of evolution acceptance by race/ethnicity can be explained by religiosity, we ran mediation analyses using a regression model-based approach in the mediation package (Tingley et al., 2014) in $\mathrm{R}$ following the methods developed by Imai et al. (2010). Mediation analyses are essentially causal in nature; however, because we are using observational and not experimental data, we tried to avoid making any causal claims in our description of the results. To estimate the mediation effect, we ran two models: the "mediator model," in which the mediator is the outcome variable and all the covariates are the predictors; and the "outcome model," in which the mediator along with the covariates are predictors. Using these two models as inputs, the mediate function calculates the estimated average mediation effect, that is, in our case the association of race/ethnicity with evolution acceptance that can be attributed to differences in religiosity of students with different racial/ethnic backgrounds. We chose to run simple mediations with religiosity as the mediator rather than religious affiliation, because religiosity is a continuous variable that lends itself better to analyses than categorical religious affiliation. Further, we hypothesized that religious affiliation broadly is not directly associated with evolution acceptance in our study population but is indirectly associated through reli- giosity. Therefore, not including religious affiliation in our mediation models does not violate the assumption of sequential ignorability made in the mediation analyses (for more details, see Imai et al. 2011). Figure 1a illustrates the model we tested. For this mediation, our "mediator model" was an LMM with religiosity as the outcome; course as a random effect with varying intercepts; and race/ethnicity, age, gender, parent education, and region as predictors. Our "outcome model" was an LMM with evolution acceptance as the outcome; course as a random effect (varying intercepts); and race/ethnicity, religiosity, age, gender, parent education, and region as predictors. We had three outcome models, one each for microevolution, macroevolution, and human evolution acceptance. We used the mediate function with our mediator models and outcome models to calculate the mediation effects. This function calculates the average mediation effects and the average direct effects of a predictor (race/ethnicity) on a response variable (acceptance of evolution) given a mediator (religiosity) using quasi-Bayesian Monte Carlo simulations to calculate confidence intervals and statistical significance of the mediation. Using "White" as the reference group and "Black/African American" as the comparison group, we ran mediation analyses for microevolution acceptance, macroevolution acceptance, and human evolution acceptance, with the number of simulations set to 1000. Next, we repeated the mediations with "Hispanic" compared with "White." We did not run mediations for Asian students, because their religiosity levels were similar to those of White students. The data and $\mathrm{R}$ script used for analyses are available in the Supplemental Material. We refer the readers to Imai et al. (2011) for a detailed description of this mediation method.

To determine whether the mediation results would be different depending on students' religious affiliation (Catholic, non-Catholic Christian, and no affiliation), we ran a moderated mediation model (Figure 1b). For these analyses, the models were the same as described earlier, but with the addition of religious affiliation as a covariate. We ran three moderated mediation models for each pair of race/ethnicity categories to estimate the mediated effect of religiosity for students with different religious affiliations (Christian-Catholic, non-Catholic Christian, and no affiliation). We did not run a moderated model for the other faith category, because it lumped together students from many vastly different faiths, making it difficult to interpret.

\section{Positionality}

We acknowledge that our research team's identities influence and potentially bias our research. M.E.B, H.M.D., G.M.S., and 
S.E.B. all identify as White, whereas K.S. identifies as South Asian, and T.M.H. identifies as Black. Our team's religious identifications include agnostic (M.E.B. and K.S.), atheist (G.M.S. and S.E.B.), Christian-Jehovah's Witness (T.M.H.), and Christian-Catholic (H.M.D.). We bring our disciplinary expertise to this work as discipline-based education researchers in biology education (M.E.B., K.S., H.M.D., T.M.H., and S.E.B.), an educational psychologist (G.M.S.), and instructors and students in undergraduate biology courses (M.E.B., H.M.D., T.M.H., and S.E.B.).

\section{RESULTS}

Population

Nine thousand six hundred and twenty students in total completed the survey with the religiosity, acceptance of evolution, and racial/ethnic identity instruments. Of these students, 581 (6\%) were Black/African American, 1585 (16\%) were Hispanic, 1512 (16\%) were Asian, 4673 (49\%) were White, and 1269 were multiracial (13\%). Twenty-six percent of students were Catholic, 28\% were non-Catholic Christian, 10\% identified with a non-Christian religion, and 36\% were nonaffiliated (atheist, agnostic, or nothing in particular). Consistent with our expectations, most Hispanic students identified as Catholic (55\%) and most Black/African American students (62\%) identified as non-Catholic Christian. Supplemental Table 1 shows the distribution of students by race/ethnicity and religious affiliation. Fewer than $2 \%$ of data were missing from students, so no imputation of data was necessary (Meade and Craig, 2012). After removing students with missing data and removing multiracial/other race/ethnicity students, we had a total of 8192 students whose data we used in our analyses. Supplemental Table 2 shows the distribution of students by region and race/ ethnicity.

\section{Rasch models}

Weighted mean-squares item fit statistics (WMNSQ, equal to infit MNSQ) were within the acceptable range for all Rasch models. WMNSQ values of 0.7 to 1.3 logits are considered acceptable, and in our case, these lay between 0.7 and 1.3 for religiosity, 0.9 and 1.2 for microevolution, 0.8 and 1.3 for macroevolution, and 0.8 and 1.4 for human evolution. All of our reliability measures had an acceptable value, that is, were greater than 0.7. The EAP/PV was 0.88 for religiosity, 0.85 for microevolution, 0.87 for macroevolution, and 0.91 for human evolution. Person reliabilities as estimated by WLE person separation index, which estimates whether a similar order of person abilities would be generated by items of similar difficulty, were 0.83 for religiosity, 0.79 for microevolution, 0.84 for macroevolution, and 0.88 for human evolution. The first eigenvalues of residuals of all our Rasch models were less than 2, indi-

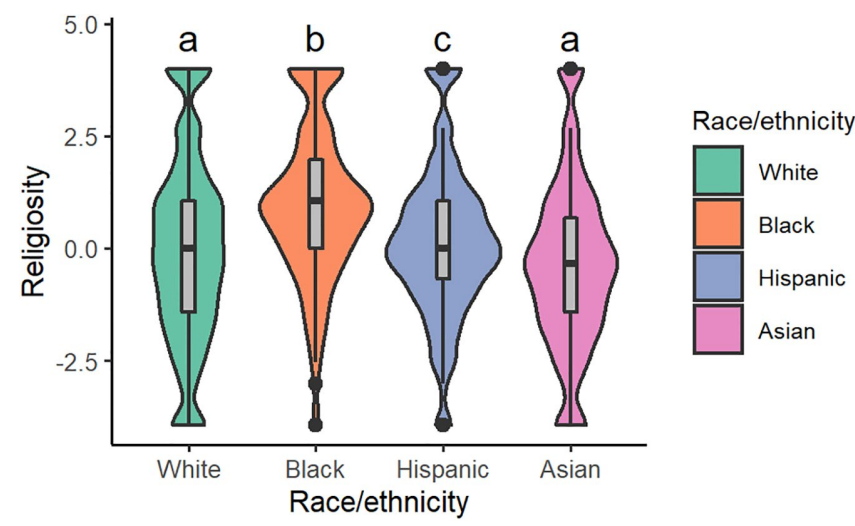

FIGURE 2. Religiosity by student racial/ethnic identity. Religiosity was estimated using a Rasch model and is on a logit scale. Violins show the distribution of the data; gray bars in the middle of the violins indicate the interquartile range, and black lines in the middle of these bars indicate the median; and black lines stretching out from the bars indicate first/third quartile \pm 1.5 interquartile range. The same letter above the violins indicates that groups are similar, and a different letter indicates that they are statistically different based on post hoc Tukey comparisons.

cating that the data were unidimensional and a unidimensional model was appropriate. See Supplemental Table 3 fit statistics for all our Rasch models.

\section{Finding 1: On Average, Black/African American Students Were More Religious Than Students with All Other Racial/ Ethnic Identities}

Pairwise contrasts show that Black/African American students were, on average, significantly more religious than students with all other racial/ethnic identities and Hispanic students were slightly more religious than Asian and White students (Figure 2 and Table 1). See Table 1 for estimated marginal means for religiosity by race/ethnicity.

\section{Finding 2: On Average, Black/African American Students Accepted Evolution Less Than Students with All Other Racial/Ethnic Identities}

Black/African American students had, on average, lower microevolution acceptance, macroevolution acceptance, and human evolution acceptance than students with any other racial/ethnic identity (all $p<0.05$ ). Hispanic students and Asian students also had lower microevolution acceptance, macroevolution acceptance, and human evolution acceptance than White students, but higher than Black/African American students (all $p<$ 0.05) (Figure 3). One explanation for the lower evolution acceptance for Asian students might be caused by their

TABLE 1. Estimated marginal means derived from an LMM for religiosity and evolution acceptance among college students with course as a random effect with varying intercepts (see Supplemental Table 4 for post hoc comparisons)

\begin{tabular}{lccccccrr}
\hline Race/ethnicity & Religiosity & SE & Microevolution & SE & Macroevolution & SE & Human evolution & SE \\
White & -0.11 & 0.074 & 0.16 & 0.067 & 0.14 & 0.068 & 0.18 & 0.084 \\
Black & 0.93 & 0.106 & -0.67 & 0.095 & -0.56 & 0.092 & -0.84 & 0.116 \\
Hispanic & 0.17 & 0.085 & -0.28 & 0.077 & -0.09 & 0.076 & -0.23 & 0.095 \\
Asian & -0.25 & 0.089 & -0.38 & 0.080 & -0.09 & 0.079 & -0.17 & 0.098 \\
\hline
\end{tabular}


a

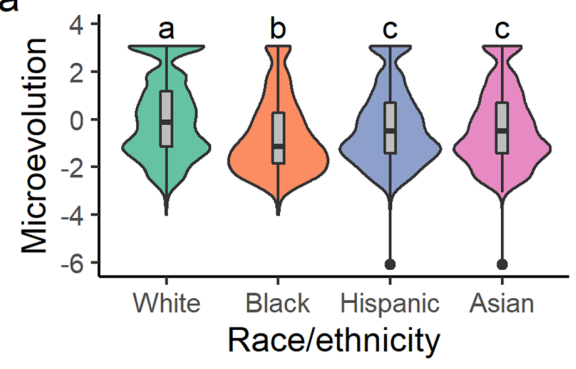

b

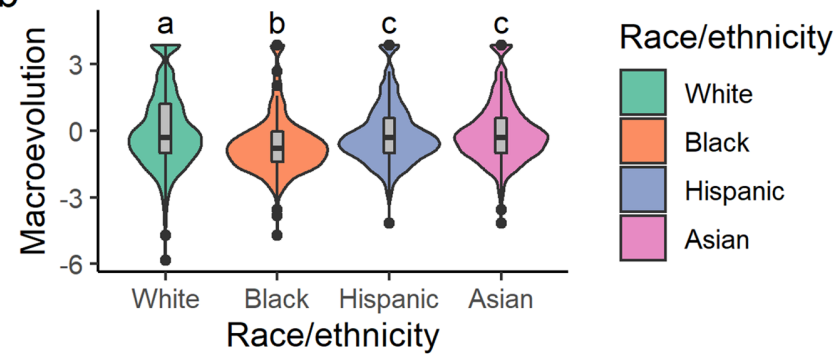

C

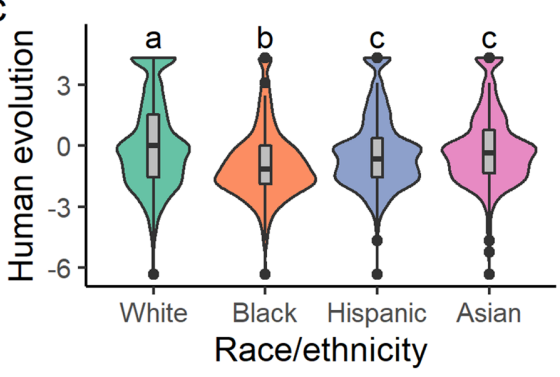

FIGURE 3. Student acceptance of (a) microevolution, (b) macroevolution, and (c) human evolution by racial/ethnic identity. All evolution acceptance measures were estimated using the Rasch models and are on a logit scale. Violins show the distribution of the data; gray bars in the middle of the violins indicate the interquartile range, and black lines in the middle of these bars indicate the median; and black lines stretching out from the bars indicate first/ third quartile \pm 1.5 interquartile range. The same letter above the violins indicates that groups are similar, and a different letter indicates that they are statistically different based on post hoc Tukey comparisons. reluctance to pick the "strongly agree" option when answering about controversial topics (Grandy, 1996; Wang et al., 2008).

\section{Finding 3: Highly Religious Black/African American and Hispanic Students Were Just as Accepting of Evolution as Highly Religious White Students}

We found that Black/African American, Hispanic, and Asian students at higher religiosity levels were just as accepting of evolution as White students, indicating no evidence that there was a compounding negative effect of religiosity and race/ethnicity on acceptance of evolution. When we plotted the relationship between religiosity and evolution acceptance disaggregated by students' racial/ethnic identities, we found that, at high religiosity levels, students of all racial/ethnic identities had similarly low levels of acceptance of evolution, but at low levels of religiosity, there were greater differences between students with different racial/ethnic identities (Figure 4). Thus, although there was a significant interaction, it was not in the direction we would have expected if a compounding negative effect of racism and secularism was present (slope contrasts in Table 2). The relationship between religiosity and evolution acceptance was weaker for students of color according to all measures of evolution acceptance (microevolution: Black/African American $[-0.07 \pm 0.04]$, Hispanic [ $-0.12 \pm 0.03]$, Asian [ $-0.12 \pm 0.02]$, and White $[-0.2 \pm 0.01]$; macroevolution acceptance: Black/ African American $[-0.15 \pm 0.03]$, Hispanic $[-0.15 \pm 0.02]$, Asian $[-0.14 \pm 0.02]$, and White $[-0.27 \pm 0.01]$; human evolution acceptance: Black/African American [-0.28 \pm 0.04$]$, Hispanic $[-0.27 \pm 0.03]$, Asian $[-0.21 \pm 0.03]$, White $[-0.39 \pm$ 0.02]; also see Supplemental Figure 5). This indicates that, although Black/African American and Hispanic students tended to be more religious, the relationship between evolution acceptance and religiosity also tended to be slightly weaker for these students.

We also found that Christian (Catholic and non-Catholic) Black/African American, Hispanic, and Asian students were just as accepting of evolution as Christian White students, once again indicating no evidence of a compounding negative effect of religious affiliation and race/ethnicity on acceptance of evolution. There was a statistically significant interaction between religious affiliation and race/ethnicity, but just as with religiosity, the interaction was in the opposite direction that we would have expected if there were a compounding effect; there were
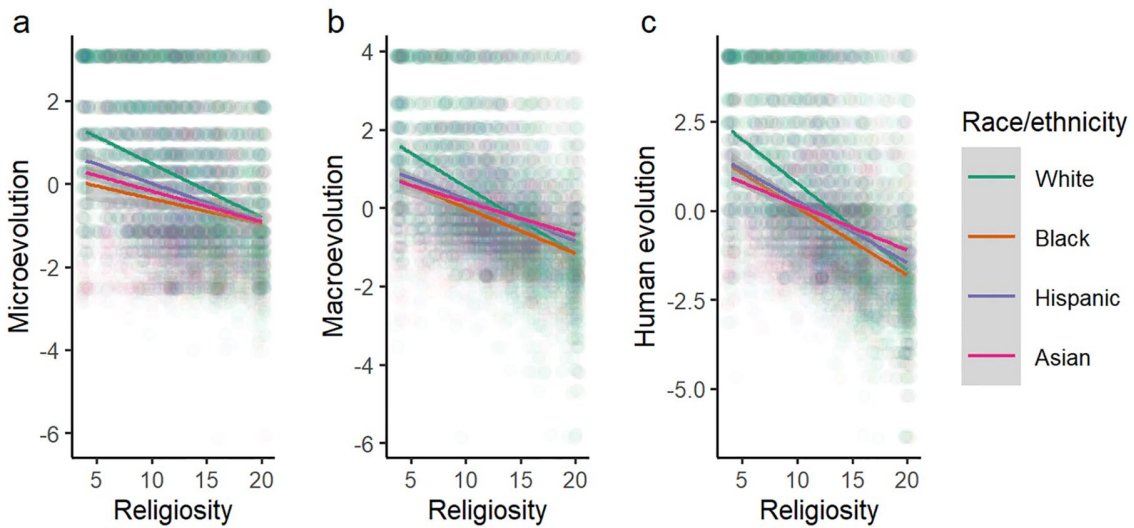

FIGURE 4. Scatter plots of evolution acceptance measures against religiosity measures with overlaid Ordinary Least Squares regression lines broken down by students' racial/ethnic identities: (a) microevolution acceptance, (b) macroevolution acceptance, and (c) human evolution acceptance. The points were jittered for clarity; darker points indicate multiple overlapping points, and gray spread around the lines indicates $95 \%$ confidence intervals. 
TABLE 2. Pairwise contrasts of estimated marginal means of slopes of the relationship between religiosity and evolution acceptance ${ }^{a}$

\begin{tabular}{|c|c|c|c|c|c|c|c|c|c|}
\hline \multirow[b]{2}{*}{ Contrast } & \multicolumn{3}{|c|}{ Microevolution } & \multicolumn{3}{|c|}{ Macroevolution } & \multicolumn{3}{|c|}{ Human evolution } \\
\hline & estimate & SE & $p$ value & Estimate & SE & $p$ value & estimate & SE & $p$ value \\
\hline White-Black & -0.14 & 0.04 & 0.004 & -0.12 & 0.04 & 0.003 & -0.11 & 0.04 & 0.06 \\
\hline White-Hispanic & -0.08 & 0.03 & 0.009 & -0.12 & 0.02 & $<0.001$ & -0.12 & 0.03 & 0.00 \\
\hline White-Asian & -0.09 & 0.03 & 0.003 & -0.14 & 0.02 & $<0.001$ & -0.18 & 0.03 & $<0.0001$ \\
\hline Black-Hispanic & 0.05 & 0.05 & 0.645 & 0.00 & 0.04 & 1.00 & -0.01 & 0.05 & 1.00 \\
\hline Black-Asian & 0.05 & 0.04 & 0.684 & -0.01 & 0.04 & 0.98 & -0.07 & 0.05 & 0.50 \\
\hline Hispanic-Asian & 0.00 & 0.03 & 0.999 & -0.02 & 0.03 & 0.95 & -0.06 & 0.04 & 0.32 \\
\hline
\end{tabular}

a Significant differences mean that the relationship between religiosity and evolution acceptance differs in steepness of the slope between the groups. These estimates were derived from LMMs for evolution acceptance among college students with course as a random effect with varying intercepts (see Supplemental Table 5 for parameter estimates of the LMMs).

bigger differences between nonreligious students with different racial/ethnic backgrounds than among Christians (Catholic and non-Catholic). There was some evidence of a compounding effect of race/ethnicity and religious affiliation in the case of microevolution acceptance (see Table 3 for pairwise contrasts within each religious affiliation and Supplemental Figures 6-8). Together, these results showed that religious background (religiosity or religious affiliation) and race/ethnicity did not have a compounding effect on evolution acceptance. Next, we explore whether the higher average religiosity of Black/African American and Hispanic students was associated with their lower evolution acceptance.

\section{Finding 4: The Religious Backgrounds of Black/African American and Hispanic Students Were Associated with Their Lower Levels of Evolution Acceptance}

Our mediation analyses revealed that a large portion of the differences between Black/Hispanic and White student evolution acceptance levels was associated with their higher than average religiosity levels. The average mediation effect of religiosity on race/ethnicity and evolution acceptance was -0.26 for microevolution acceptance, -0.32 for macroevolution, and -0.47 for human evolution acceptance (all $p<0.001$ ). However, regardless of the evolution acceptance measure, a large proportion of the difference in evolution acceptance between White and Black/African American students was associated with religiosity (32\% for microevolution acceptance, $48 \%$ for macroevolution acceptance, and 49\% for human evolution acceptance;
Table 4). Religiosity was also a strong mediator for macroevolution and human evolution acceptance among Hispanic students (67\% and 50\%, respectively) and a weaker mediator of microevolution acceptance (22\%).

These results illustrate that Black/African American students, on average, had lower levels of evolution acceptance than students from any other race/ethnicity and their higher than average religiosity was associated with the different levels of evolution acceptance between Black/African American and White students. Hispanic students only had slightly lower levels of evolution acceptance than White students, and their higher than average religiosity was also associated with that difference.

The mediation results were similar when broken down by Catholic, non-Catholic Christian, and unaffiliated students. Our moderated mediation analyses with religiosity as the mediator and religious affiliation (Catholic, non-Catholic Christian, and no affiliation) as the moderator (Figure 1) did not yield any significant differences between religious affiliations (Table 5; see full results, including confidence intervals for the estimates, in the Supplemental Material). For example, the proportion mediated by religiosity was $10 \%$ for microevolution acceptance, $23-24 \%$ for macroevolution acceptance, and 24\% for human evolution acceptance, respectively, for Catholics, non-Catholic Christians, and those who were not affiliated with any religion. For Hispanic and White students, even though the mediation effect was similar across affiliations, this moderated mediation model showed a low mediation effect, suggesting that religious affiliation was associated with most of the effect of religious

TABLE 3. Pairwise contrasts of estimated marginal means of the relationship between religious affiliation and evolution acceptance ${ }^{a}$

\begin{tabular}{|c|c|c|c|c|c|c|c|c|c|c|}
\hline \multirow[b]{2}{*}{ Religion } & \multirow[b]{2}{*}{ Contrast } & \multicolumn{3}{|c|}{ Microevolution } & \multicolumn{3}{|c|}{ Macroevolution } & \multicolumn{3}{|c|}{ Human evolution } \\
\hline & & estimate & SE & $p$ value & estimate & SE & $p$ value & estimate & SE & $p$ value \\
\hline No affiliation & Black-White & -0.93 & 0.16 & $<0.001$ & -0.60 & 0.15 & $<0.001$ & -0.65 & 0.18 & $<0.01$ \\
\hline No affiliation & Asian-White & -0.99 & 0.08 & $<0.001$ & -0.77 & 0.07 & $<0.001$ & -1.03 & 0.09 & $<0.001$ \\
\hline Catholic & Black-White & -0.40 & 0.18 & 0.25 & -0.21 & 0.16 & 1.00 & -0.12 & 0.20 & 1.00 \\
\hline Catholic & Hispanic-White & -0.21 & 0.08 & 0.08 & -0.09 & 0.07 & 1.00 & -0.12 & 0.09 & 1.00 \\
\hline Non-Catholic Christian & Hispanic-White & -0.10 & 0.11 & 1.00 & 0.11 & 0.10 & 1.00 & -0.15 & 0.13 & 1.00 \\
\hline Non-Catholic Christian & Asian-White & -0.40 & 0.13 & 0.02 & -0.08 & 0.12 & 1.00 & -0.29 & 0.15 & 0.42 \\
\hline
\end{tabular}

aThese estimates were derived from LMMs for evolution acceptance among college students with course as a random effect with varying intercepts (see Supplemental Table 6 for parameter estimates of the LMMs). 
TABLE 4. Results from the mediation analyses using 1000 quasi-Bayesian Monte Carlo simulations to calculate confidence intervals and statistical significance ${ }^{a}$

\begin{tabular}{|c|c|c|c|c|c|c|c|}
\hline & & \multicolumn{3}{|c|}{ Black/African American } & \multicolumn{3}{|c|}{ Hispanic } \\
\hline & & Estimate & 95\% CI lower & 95\% CI upper & Estimate & 95\% CI lower & 95\% CI upper \\
\hline \multirow[t]{4}{*}{ Microevolution } & Mediation effect & -0.26 & -0.30 & -0.21 & -0.07 & -0.11 & -0.04 \\
\hline & Direct effect & -0.55 & -0.70 & -0.41 & -0.25 & -0.35 & -0.15 \\
\hline & Total effect & -0.81 & -0.96 & -0.66 & -0.33 & -0.43 & -0.21 \\
\hline & Prop. mediated & 0.32 & 0.26 & 0.4 & 0.23 & 0.14 & 0.36 \\
\hline \multirow[t]{4}{*}{ Macroevolution } & Mediation effect & -0.32 & -0.37 & -0.27 & -0.09 & -0.13 & -0.05 \\
\hline & Direct effect & -0.34 & -0.46 & -0.21 & 0.05 & -0.14 & 0.05 \\
\hline & Total effect & -0.66 & -0.79 & -0.53 & -0.14 & -0.24 & -0.04 \\
\hline & Prop. mediated & 0.48 & 0.40 & 0.60 & 0.67 & 0.34 & 1.96 \\
\hline \multirow[t]{4}{*}{ Human evolution } & Mediation effect & -0.47 & -0.55 & -0.4 & -0.14 & -0.19 & -0.08 \\
\hline & Direct effect & -0.49 & -0.63 & -0.36 & -0.13 & -0.24 & -0.01 \\
\hline & Total effect & -0.96 & -1.13 & -0.78 & -0.27 & -0.40 & -0.14 \\
\hline & Prop. mediated & 0.49 & 0.41 & 0.58 & 0.51 & 0.30 & 0.92 \\
\hline
\end{tabular}

${ }^{a}$ Mediation effect indicates the amount of the association of racial/ethnic identity with evolution acceptance that is mediated by religiosity; it is essentially an estimate of the average change in evolution acceptance corresponding to what would be observed if the measures of religiosity observed among Black/Hispanic students were to change to the values observed among White students. Direct effect indicates the amount of the association of racial/ethnic identity with evolution acceptance not related to religiosity. Proportion ("Prop.") mediated shows the proportion of total association of racial/ethnic identity with evolution acceptance that can be attributed to religiosity. Bolded estimates indicate $p<0.05$.

background on evolution acceptance and not religiosity (Table 5). This is because Hispanic students were not significantly more religious than White students once religious affiliation and other covariates such as gender, age, region, and parents' level of education were accounted for. However, Black/ African American students were more religious than White students, even after controlling for religious affiliation and covariates (Supplemental Figure 9). Together, these results show that religious background was an important mediator for the relationship between race/ethnicity and evolution acceptance. The difference in evolution acceptance between White and Hispanic students was largely explained by the higher likelihood of Hispanic students identifying as Catholic. However, both religiosity and religious affiliation contributed to the difference in evolution acceptance between White and Black/African American students.

\section{DISCUSSION}

This study shows that higher levels of religiosity and religious affiliation among Black/African American and Hispanic students can be a factor associated with their lower levels of evolution acceptance. Particularly, we found that Black/African American students had the highest levels of religiosity and lowest levels of evolution acceptance among students from all racial/ethnic backgrounds. Hispanic students had slightly higher levels of religiosity compared with White and Asian students and slightly lower evolution acceptance compared with White students. These results are in line with results from other studies that measured related constructs (Bailey et al., 2011; Mead et al., 2015; Salazar et al., 2019), but our study uniquely conducted mediation analyses to show that lower rates of evolution acceptance among Black/African American college biology students were mediated by their higher than average religiosity. We also uniquely show that slightly lower levels of evolution acceptance among Hispanic biology students were mediated by their slightly higher levels of religiosity. Finally, this study revealed very little evidence of a compounding effect of racism and secularism on evolution acceptance; however, experiencing both racism and secularism in evolutionary biology at the same time could affect evolution acceptance in other more complex ways that cannot be captured through a quantitative study. Overall, these data illustrate that religious identity is important to consider for evolution education outcomes for Black/African American and Hispanic students.

\section{Religiosity as a Support for Students, not a Deficit}

It is often the discourse in science community (often from nonreligious White men) that a religious identity is not valuable to students or the science community (Dawkins, 2009; Coyne, 2015; Krauss, 2015), but this is a potentially destructive perception for some Black/African American students. Indeed, prior STEM education theory highlights the unique cultural capital that students of color bring to STEM environments (Yosso, 2005) and religion may be important cultural capital. Research and history document that Black/African American individuals have used religion as unique cultural capital in their lives and in their education. Christian Protestantism was, and continues to be, an important part of Black/African American culture that can help mitigate the negative effects of racism and oppression by providing meaning and social support for individuals in these communities. Indeed, longitudinal data have revealed that religious involvement among African American individuals moderates the effects of racism on psychological distress (Ellison et al., 2008). This importance of religion to the lives of Black/African Americans has been documented for at least 40 years (Taylor et al., 1996, 2003), but can partially be traced back to enslaved Africans in the United States who were often not able to practice the traditions of their native religious cultures (Weisenfeld, 2015). Enslaved Africans and their African American children created robust and unique Christian religious cultures that helped them endure their dehumanization and oppression (Weisenfeld, 2015; Grendler et al., n.d.). After 
TABLE 5. Results from the moderated mediation analyses using 1000 quasi-Bayesian Monte Carlo simulations to calculate confidence intervals and statistical significance ${ }^{a}$

\begin{tabular}{|c|c|c|c|c|}
\hline \multicolumn{5}{|c|}{ Black/White } \\
\hline & & Catholic & Non-Catholic Christian & No affiliation \\
\hline \multirow[t]{4}{*}{ Microevolution } & Mediation effect & -0.05 & -0.05 & -0.05 \\
\hline & Direct effect & -0.48 & -0.48 & -0.49 \\
\hline & Total effect & -0.54 & -0.54 & -0.54 \\
\hline & Prop. mediated & 0.10 & 0.10 & 0.10 \\
\hline \multirow[t]{4}{*}{ Macroevolution } & Mediation effect & -0.07 & -0.07 & -0.07 \\
\hline & Direct effect & -0.24 & -0.24 & -0.24 \\
\hline & Total effect & -0.31 & -0.31 & -0.31 \\
\hline & Prop. mediated & 0.23 & 0.24 & 0.23 \\
\hline \multirow[t]{4}{*}{ Human evolution } & Mediation effect & -0.11 & -0.11 & -0.11 \\
\hline & Direct effect & -0.34 & -0.34 & -0.34 \\
\hline & Total effect & -0.45 & -0.45 & -0.45 \\
\hline & Prop. mediated & 0.24 & 0.24 & 0.24 \\
\hline \multicolumn{5}{|c|}{ Hispanic/White } \\
\hline \multirow[t]{4}{*}{ Microevolution } & Mediation effect & 0.00 & 0.00 & 0.00 \\
\hline & Direct effect & -0.24 & -0.25 & -0.25 \\
\hline & Total effect & -0.24 & -0.25 & -0.25 \\
\hline & Prop. mediated & 0.00 & 0.00 & 0.00 \\
\hline \multirow[t]{4}{*}{ Macroevolution } & Mediation effect & 0.00 & 0.00 & 0.00 \\
\hline & Direct effect & -0.09 & -0.09 & -0.09 \\
\hline & Total effect & -0.09 & -0.09 & -0.09 \\
\hline & Prop. mediated & 0.01 & 0.01 & 0.03 \\
\hline \multirow[t]{4}{*}{ Human evolution } & Mediation effect & 0.00 & 0.00 & 0.00 \\
\hline & Direct effect & -0.20 & -0.21 & -0.21 \\
\hline & Total effect & -0.21 & -0.21 & -0.21 \\
\hline & Prop. mediated & 0.03 & 0.01 & 0.01 \\
\hline
\end{tabular}

${ }^{a}$ Mediation effect indicates the amount of the association of racial/ethnic identity with evolution acceptance that is mediated by religiosity after controlling for religious affiliation. Direct effect indicates the amount of the association of racial/identity with evolution acceptance not related to religiosity. Proportion ("Prop.") mediated shows the proportion of total association of racial/ethnic identity with evolution acceptance that can be attributed to religiosity. Bolded estimates indicate $p<0.05$. See Supplemental Table 7 for full moderation mediation output, including $95 \%$ confidence intervals.

the Civil War, Christian religion was closely associated with the education and social mobilization of African Americans, because Christian organizations helped to establish churches and educational institutions among African Americans (Weisenfeld, 2015). Therefore, it is important that mentors and instructors in biology recognize the value of religion in the lives of their students.

\section{Diversifying Evolutionary Biology}

Given that the field of evolutionary biology awards very few PhDs to Black/African American students, the outcomes from this study should be concerning if we aim to diversify evolutionary biology. Mead et al. (2015) reported that only one PhD was awarded to an African American student in evolutionary biology in the year 2011, and current data suggest that these numbers have not improved. We aggregated data from 2015 to 2017 from the National Center for Education Statistics, which tracks $\mathrm{PhDs}$ awarded nationwide, and compared $\mathrm{PhDs}$ awarded in different biology subfields to students with different racial/ethnic identities (Figure 5). We found that underrepresentation of Black/African American students was greater in the fields of evolutionary biology and ecology compared with biomedicine or nursing. While the biomedical and nursing sciences awarded 5 and $10 \%$ of their PhDs to Black/African American students, ecology and evolutionary biology both only awarded $1 \%$ of their PhDs to Black/African American students. Further, we found that Black/African American students are represented less in these fields than students from all other racial/ethnic identities (Figure 5). In terms of recruiting and retaining Black/ African American students, evolutionary biology and closely related fields are falling short, and this has not improved since at least 2011.

Prior research shows that evolution instructors are hesitant to discuss interactions between science and religion while teaching evolution (Barnes and Brownell, 2016), but this current study reveals how this could be particularly disadvantageous to Black/African American and Hispanic religious students. Our prior work has advocated for the use of Religious Cultural Competence in Evolution Education (ReCCEE) as a means to improve the evolution education outcomes for religious college biology students (Barnes and Brownell, 2017); these data suggest that this framework may be particularly 
PhDs awarded by field and student race/ethnicity $(2015$ - 2017)

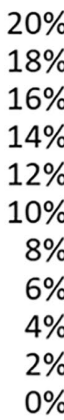

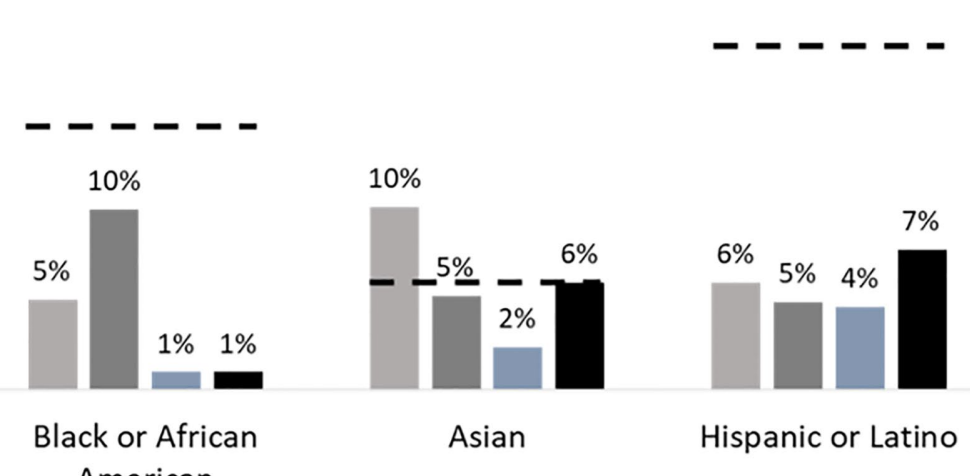

American
Nursing PhDs
Evolutionary Biology PhDs

- - - General US population

FIGURE 5. Data adapted from the National Center for Education Statistics (2015-2017) illustrating the percent of PhDs awarded to students, broken down by field and student racial/ethnic identity. The dashed line represents the percent of individuals with each racial/ethnic identity in the general U.S. population from the most recent U.S. census data (2010). If the bar does not reach the dashed line, then these students are considered underrepresented in each field.

beneficial for religious Black/African American students. The instructional practices that fall under the umbrella of ReCCEE could help these students reduce their perceived conflict between religion and evolution (Barnes et al., 2017a; Truong et al., 2018). For instance, one ReCCEE practice includes highlighting relevant religious scientist role models who accept evolution (Barnes and Brownell, 2017; Holt et al., 2018). One of the prior studies examining evolution education outcomes of African American students found that these students placed emphasis on the importance of role models in a discipline for guiding their interests (Mead et al., 2015). One such role model that evolution instructors could introduce to students is Dr. Joseph Graves, a prominent African American evolutionary biologist who considers himself part of a religious community. He was the first African American to ever earn a PhD in evolutionary biology (Graves, 2004) and was an author on both prior studies that explored the evolution education outcomes of African American students (Bailey et al., 2011; Mead et al., 2015).

This study highlights how important it is to consider not only race/ethnicity in terms of diversity efforts, but also the relationship between race/ethnicity and religiosity. One explanation for why Black/African Americans continue to be so severely underrepresented in evolutionary biology, despite national efforts to diversify based on race/ethnicity, could be that there is an implicit, and sometimes explicit, bias against evangelical Protestant Christians in science. Christian college students believe they are negatively stereotyped about their ability in science and experience stereotype threat on assessments they believe are measuring their scientific ability (Rios et al., 2015). Further, biology faculty members rate evangelical Christian students as less competent, less hireable, and less lik- able when evaluating them for a biology PhD program (Barnes et al., 2020a). Therefore, Black/African American students may be concerned about how they are perceived based on their religious identity and may experience stereotype threat based on their religious identity in addition to their racial identity. This implies that we must be conscious of the relationship between Black/African American identity and religiosity.

\section{Intersectionality and Interaction Effects between Race/ethnicity and Religion}

Although we found evidence for mediations, we did not find the same evidence for a compounding negative effect of race/ ethnicity and religion on students' evolution acceptance. The results from the interactions between race/ethnicity and religiosity for evolution acceptance were significant, but these results indicated larger differences between students from different race/ethnicities at lower levels of religiosity and not at higher levels of religiosity. This could mean that other differences between groups of students, such as knowledge of evolution, history of evolution in supporting racism, and differences in how one responds to surveys based on cultural differences, could exacerbate the differences between groups of students when they are less religious. Further, although Black/African American and Hispanic students were more religious on average than White students were, the relationship between high religiosity and low evolution acceptance was stronger among White students than Hispanic and Black/African American students. This indicates that perhaps highly religious Black/African American and Hispanic students are attempting to reconcile their religious beliefs with evolution to a greater extent than highly religious White students.

\section{The Importance of Disaggregating Racial/ethnic Minori- ties in Evolution Education Studies}

We found different results for Hispanic and Black/African American students, and this suggests researchers should avoid aggregating these students into a single group in evolution education studies. Compared with White and Asian students, we found that Hispanic students had slightly higher religiosity measures, and this mediated their slightly lower evolution acceptance measures. However, Black/African American students were much more religious and much less accepting of evolution on all measures, which we would not have been able to determine had we aggregated these students with Hispanic students. Further, we also were able to show that, for Hispanic students, being Catholic was more important than the strength of their religiosity for explaining their evolution acceptance.

We also were able to show that Asian students, on average, had slightly lower evolution acceptance than White students, even though they had similar levels of religiosity. In one previous 
study, it was also found that Asian students, on average, accepted evolution slightly less than White students (Sbeglia and Nehm, 2018). This finding warrants further exploration. Prior studies on Asian student survey response patterns suggests Asian students might not accept evolution less but that they may have been avoiding the "strongly agree" options due to cultural norms. Past studies indicate that Asian students may avoid extreme response options, particularly when answering questions about topics such as evolution that might be perceived of as controversial (Grandy, 1996; Wang et al., 2008), and this could explain these results. However, in other studies, Asian students have been grouped in with other non-White students (Metzger et al., 2018) or aggregated with White students to compare them to Black, Latino, or Hispanic students (Salazar et al., 2019). These results highlight some of the methodological issues that arise when researchers are categorizing Asian students and indicate that researchers should consider evaluating Asian students as a separate group in future analyses.

\section{LIMITATIONS AND FUTURE RESEARCH}

We did not include other variables in our models that are related to students' evolution acceptance (such as understanding of evolution), which could have improved the accuracy of our estimates, and we encourage future research to consider these variables. Further, we did disaggregate among racial/ethnic groups in this study, but we could have disaggregated students even further. For instance, we did not disaggregate African American students from Black students who are not American (i.e., Black students who were born in Africa or the Caribbean) or from Black students who are not African (i.e., Jamaican or Haitian students), and these students could have different levels of evolution acceptance and may have different average levels of religiosity. Also, we did not disaggregate Asian students, even though Chinese, Filipino, Indian, Korean, Japanese, Vietnamese, and other South Asian and Southeast Asian students have been shown to have different educational outcomes in studies (Kim, 2002; Nguyen et al., 2015). We were also not able to disaggregate students who identified with multiple race/ethnicities or students who are international. Ultimately, this illustrates some of the limitations of using a quantitative survey to capture a social construct that is as complex as race/ethnicity. Future qualitative work can help illuminate some of the potential nuances of the interactions between race/ethnicity and religiosity on students' evolution acceptance.

Religiosity only partially mediated Black/African American and Hispanic students' lower evolution acceptance, so religiosity is not the only factor influencing these students' evolution acceptance. This is an important area for future research to explore, and it is likely that prior injustices committed against Black people from the scientific community and the unique history of scientists using evolution in racist ideology plays a role in Black/African American perceptions of evolution. In the past, some people have used evolution to justify racist and oppressive policies and the dehumanization of other races/ ethnicities (Graves, 2004, 2019; Coyne, 2015; Bailey et al., 2011; Donovan et al., 2019). Since the 19th century, people have often attributed atrocities such as the eugenics movement and racial injustices during the Second World War to the emergence of evolutionary thinking (Numbers, 2006). Even recently, college students reported thinking that accepting evo- lution leads to society becoming more racist (Brem et al., 2003), and many African American students at a historically black college agreed that evolution is a racist theory (Bailey et al., 2011). To our knowledge, no research has explored whether Black/African American college biology students have these concerns to a greater extent than students of other racial/ethnic identities and how this might be related to their experiences while learning evolution. Important future research would be to explore how these factors may interact with Black/African American students' experiences while learning evolution.

\section{CONCLUSIONS}

In this nationwide study, we found that Black/African American college biology students, on average, are less accepting of evolution than Hispanic, Asian, and White students. Further, we found that Black/African American students' higher than average religiosity mediated their lower than average evolution acceptance. Hispanic students were slightly less accepting of evolution than White students, which was mediated by their slightly higher rates of religiosity. These data have implications for increasing diversity within evolutionary biology. If the evolution education community wants to attract and retain diverse talent, then perhaps it is not sufficient to only focus our efforts on initiatives based on race/ethnicity, but we must also create inclusive evolution education for Black/African American and Hispanic individuals with religious beliefs.

\section{ACKNOWLEDGMENTS}

This material is based upon work supported by the National Science Foundation under grant numbers DGE-1311230 and 1712188. Any opinions, findings, and conclusions or recommendations expressed in this material are those of the author(s) and do not necessarily reflect the views of the National Science Foundation. We would like to thank Sarah Eddy for her feedback on the analyses from this article, Bryan Dewsbury and Joseph Graves for their feedback on the early ideas of the article, and the ASU Biology Education Research Lab for their feedback on drafts of the article. We would like to thank the instructors of these courses for distributing the surveys and the thousands of students who took the time to compelte them.

\section{REFERENCES}

AAPA. (2019). AAPA Statement on Race \& Racism. Pew Research Center's Religion \& Public Life Project. https://physanth.org/about/position -statements/aapa-statement-race-and-racism-2019/

American Association for the Advancement in Science. (2011). Vision and change in undergraduate biology education: A call to action. Washington, DC.

Bailey, G., Han, J., Wright, D., \& Graves, J. L. (2011). Religiously expressed fatalism and the perceived need for science and scientific process to empower agency. International Journal Science in Society, 2(3), 55-88.

Baker, J. O. (2013). Acceptance of evolution and support for teaching creationism in public schools: The conditional impact of educational attainment. Journal for the Scientific Study of Religion, 52(1), 216-228. https:// doi.org/10.1111/jssr.12007

Ballen, C. J., Aguillon, S. M., Awwad, A., Bjune, A. E., Challou, D., Drake, A. G., ... \& Cotner, S. (2019). Smaller classes promote equitable student participation in STEM. BioScience, 69(8), 669-680. https://doi.org/10.1093/ biosci/biz069

Barnes, M. E., \& Brownell, S. E. (2016). Practices and perspectives of college instructors on addressing religious beliefs when teaching evolution 
CBE-Life Sciences Education, 15(2), 1-19. https://doi.org/10.1187/ cbe.15-11-0243

Barnes, M. E., \& Brownell, S. E. (2017). A call to use cultural competence when teaching evolution to religious college students: Introducing religious cultural competence in evolution education (ReCCEE). CBE-Life Sciences Education, 16(4), es4. https://doi.org/10.1187/ cbe.17-04-0062

Barnes, M. E., \& Brownell, S. E. (2018). Experiences and practices of evolution instructors at Christian universities that can inform culturally competent evolution education. Science Education, 102(1), 36-59. https://doi .org/10.1002/sce.21317

Barnes, M. E., Dunlop, H. M., Holt, E. A., Zheng, Y., \& Brownell, S. E. (2019). Different evolution acceptance instruments lead to different research findings. Evolution: Education and Outreach, 12(1), 4. https://doi .org/10.1186/s12052-019-0096-z

Barnes, M. E., Elser, J., \& Brownell, S. E. (2017a). Impact of a short evolution module on students' perceived conflict between religion and evolution American Biology Teacher, 79(2), 104-111. https://doi.org/10.1525/ abt.2017.79.2.104

Barnes, M. E., Truong, J. M., \& Brownell, S. E. (2017b). Experiences of Judeo-Christian students in undergraduate biology. CBE-Life Sciences Education, 16(1), ar15. https://doi.org/10.1187/cbe.16-04-0153

Barnes, M. E., Truong, J. M., Grunspan, D. Z., \& Brownell, S. E. (2020a). Are scientists biased against Christians? Exploring real and perceived bias against Christians in academic biology. PLOS ONE, 15(1), e0226826.

Barnes, M. E., Werner, R., \& Brownell, S. E. (2020b). Differential Impacts of Religious Cultural Competence on Students' Perceived Conflict with Evolution at an Evangelical University. American Biology Teacher, 82, 93-101. https://doi.org/10.1525/abt.2020.82.2.93

Boone, W. J. (2016). Rasch analysis for instrument development: Why, when and how? CBE-Life Sciences Education, 15(4), rm4. https://doi .org/10.1187/cbe.16-04-0148

Brem, S. K., Ranney, M., \& Schindel, J. (2003). Perceived consequences of evolution: College students perceive negative personal and social impact in evolutionary theory. Science Education, 87(2), 181-206. https:// doi.org/10.1002/sce.10105

Cohen, A. B., Shariff, A. F., \& Hill, P. C. (2008). The accessibility of religious beliefs. Journal of Research in Personality, 42(6), 1408-1417. https://doi .org/10.1016/j.jrp.2008.06.001

Collins, P. H. (1986). Learning from the outsider within: The sociological significance of Black feminist thought. Social Problems, 33, s14-s32. https://doi.org/10.2307/800672

Collins, P. H. (1990). Black feminist thought: Knowledge, consciousness, and the politics of empowerment

Combahee River Collective. (1983). The Combahee River Collective statement. In Smith B., (Ed.), Homegirls: A Black feminist anthology (pp. 264 274). New York: Kitchen Table, Women of Color Press. (Original work published 1977.)

Cooper, K. M., Krieg, A., \& Brownell, S. E. (2018). Who perceives they are smarter? Exploring the influence of student characteristics on student academic self-concept in physiology. Advances in Physiology Education, 42(2), 200-208. https://doi.org/10.1152/advan.00085.2017

Coyne, J. A. (2015). Faith versus fact: Why science and religion are incompatible. Penguin.

Crenshaw, K. (1989). Demarginalizing the intersection of race and sex: A black feminist critique of antidiscrimination doctrine, feminist theory and antiracist politics. U. Chi. Legal f., 1989(1), 139-167.

Davis, A. Y. (1983). Women, race and class. New York: Random House.

Dawkins, R. (2009). The god delusion. New York: Random House.

Dingemans, E., \& Van Ingen, E. (2015). Does religion breed trust? A cross-national study of the effects of religious involvement, religious faith, and religious context on social trust. Journal for the scientific study of religion, 54(4), 739-755.

Donovan, B. M., Semmens, R., Keck, P., Brimhall, E., Busch, K. C., Weindling M., ... \& Salazar, B. (2019). Toward a more humane genetics education: Learning about the social and quantitative complexities of human genetic variation research could reduce racial bias in adolescent and adult populations. Science Education, 103(3), 529-560. https://doi.org/10.1002/ sce. 21506
Dunk, R. D. P., Barnes, M. E., Reiss, M. J., Alters, B., Asghar, A., Carter, B. E., ... \& Wiles, J. R. (2019). Evolution education is a complex landscape. Nature Ecology \& Evolution, 3(3), 327. https://doi.org/10.1038/s41559-019 $-0802-9$

Dunk, R. D. P., Petto, A. J., Wiles, J. R., \& Campbell, B. C. (2017). A multifactorial analysis of acceptance of evolution. Evolution: Education and Outreach, 10, 4. https://doi.org/10.1186/s12052-017-0068-0

Ecklund, E. H., Scheitle, C. P., \& Peifer, J. (2018). The religiosity of academic scientists in the United Kingdom: assessing the role of discipline and department status. Journal for the Scientific Study of Religion, 57(4), 743757. https://doi.org/10.1111/jssr.12552

Eddy, S. L., Brownell, S. E., Thummaphan, P., Lan, M.-C., \& Wenderoth, M. P. (2015). Caution, student experience may vary: Social identities impact a student's experience in peer discussions. CBE-Life Sciences Education 14(4), ar45. https://doi.org/10.1187/cbe.15-05-0108

Ellison, C. G., Musick, M. A., \& Henderson, A. K. (2008). Balm in Gilead: Racism, religious involvement, and psychological distress among African-American adults. Journal for the Scientific Study of Religion, 47(2) 291-309. https://doi.org/10.1111/j.1468-5906.2008.00408.x

Estrada, M., Young, G. R., Nagy, J., Goldstein, E. J., Ben-Zeev, A., MárquezMagaña, L., \& Eroy-Reveles, A. (2019). The influence of microaffirmations on undergraduate persistence in science career pathways. CBE-Life SCiences Education, 18(3), ar40. https://doi.org/10.1187/cbe.19-01-0012

Gallup. (2019). 40\% of Americans Believe in Creationism. Gallup.Com Retrieved August 31, 2019, from https://news.gallup.com/poll/261680/ americans-believe-creationism.aspx

Glaze, A. L., Goldston, M. J., \& Dantzler, J. (2014). Evolution in the southeastern USA: Factors influencing acceptance and rejection in pre-service science teachers. International Journal of Science and Mathematics Education, 13(6), 1189-1209. https://doi.org/10.1007/s10763-014-9541-1

Grandy, J. (1996). Differences in the survey responses of Asian American and White science and engineering students. ETS Research Report Series 1996(2), i-23. https://doi.org/10.1002/j.2333-8504.1996.tb01703.x

Graves, J. L. (2004). The race myth: Why we pretend race exists in America. New York: Dutton.

Graves, J. L. (2019). African Americans in evolutionary science: Where we have been, and what's next. Evolution: Education and Outreach, 12(1), 18 https://doi.org/10.1186/s12052-019-0110-5

Grendler, M., Leiter, A., and Sexton, J., compilers. (n.d.). North American Slave Narratives: Guide to Religious Content in Slave Narratives. Retrieved February 15, 2020, from https://docsouth.unc.edu/neh/religiouscontent html

Holdren, J. P., Lander, E. S., Varmus, H., \& others. (2010). Prepare and inspire: K-12 education in science, technology, engineering, and math (STEM) for America's future (Executive Report). Washington, DC: President's Council of Advisors on Science and Technology.

Holt, E. A., Ogden, T. H., \& Durham, S. L. (2018). The positive effect of role models in evolution instruction. Evolution: Education and Outreach, 11(1), 11. https://doi.org/10.1186/s12052-018-0086-6

hooks, b. (1981). Ain't I a woman? Black women and feminism. Boston: South End.

Hurtado, S., Han, J. C., Sáenz, V. B., Espinosa, L. L., Cabrera, N. L., \& Cerna, O. S. (2007). Predicting transition and adjustment to college: Biomedica and behavioral science aspirants' and minority students' first year of college. Research in Higher Education, 48(7), 841-887.

Imai, K., Keele, L., \& Tingley, D. (2010). A general approach to causal mediation analysis. Psychological Methods, 15(4), 309.

Imai, K., Keele, L., Tingley, D., \& Yamamoto, T. (2011). Unpacking the black box of causality: Learning about causal mechanisms from experimental and observational studies. American Political Science Review, 105(4), 765-789.

Jordt, H., Eddy, S. L., Brazil, R., Lau, I., Mann, C., Brownell, S. E., ... \& Freeman, S. (2017). Values affirmation intervention reduces achievement gap between underrepresented minority and white students in introductory biology classes. CBE-Life Sciences Education, 16(3), ar41.

Kim, R. Y. (2002). Ethnic differences in academic achievement between Vietnamese and Cambodian children: Cultural and structural explanations. Sociological Quarterly, 43(2), 213-235. https://doi.org/10.1111/ j.1533-8525.2002.tb00047.x 
Krauss, L. (2015, September 8). All scientists should be militant atheists. The New Yorker. Retrieved February 15, 2020, from www.newyorker.com/ news/news-desk/all-scientists-should-be-militant-atheists

Lenth, R., Singmann, H., Love, J., Buerkner, P., \& Herve, M. (2018). Emmeans: Estimated marginal means, aka least-squares means. $R$ Package Version, 1(1), 3. Retrieved February 3, 2020, from https://rdrr.io/cran/emmeans/

Linacre, J. M., \& Wright, B. D. (1993). A user's guide to BIGSTEPS: Rasch-model computer program. San Diego: Mesa Press.

Lorde, A. (1984). Sister outsider. Berkeley, CA: Crossing Press.

Mead, L. S., Clarke, J. B., Forcino, F., \& Joseph, L. G., Jr. (2015). Factors influencing minority student decisions to consider a career in evolutionary biology. Evolution: Education and Outreach, 8(1), 1-11. https://doi .org/10.1186/s12052-015-0034-7

Meade, A. W., \& Craig, S. B. (2012). Identifying careless responses in survey data. Psychological Methods, 17(3), 437.

Meaders, C. L., Toth, E. S., Lane, A. K., Shuman, J. K., Couch, B. A., Stains, M., .. \& Smith, M. K. (2019). "What will I experience in my college STEM courses?" An investigation of student predictions about instructional practices in introductory courses. CBE-Life Sciences Education, 18(4), ar60. https://doi.org/10.1187/cbe.19-05-0084

Metzger, K. J., Montplaisir, D., Haines, D., \& Nickodem, K. (2018). Investigating undergraduate health sciences students' acceptance of evolution using MATE and GAENE. Evolution: Education and Outreach, 11(1), 10. https:// doi.org/10.1186/s12052-018-0084-8

Mooney, M. (2010). Religion, college grades, and satisfaction among students at elite colleges and universities. Sociology of Religion, 71(2), 197-215.

Morton, T. R., \& Parsons, E. C. (2018). \#BlackGirlMagic: The identity conceptualization of Black women in undergraduate STEM education. Science Education, 102(6), 1363-1393. https://doi.org/10.1002/sce.21477

Nadelson, L. S., \& Southerland, S. (2012). A more fine-grained measure of students' acceptance of evolution: Development of the Inventory of Student Evolution Acceptance-I-SEA. International Journal of Science Education, 34(11), 1637-1666. https://doi.org/10.1080/09500693.2012.702235

Nguyen, D., Mai, B., Hoa Nguyen, M., Teranishi, R. T., \& Hune, S. (2015). The hidden academic opportunity gaps among Asian Americans and Pacific Islanders: What disaggregated data reveals in Washington State. Retrieved March 15, 2020, from https://vtechworks.lib.vt.edu/handle/10919/84013

O'Brien, L. T., Bart, H. L., \& Garcia, D. M. (2020). Why are there so few ethnic minorities in ecology and evolutionary biology? Challenges to inclusion and the role of sense of belonging. Social Psychology of Education. https://doi.org/10.1007/s11218-019-09538-x

Pew. (2009a). Religious differences on the question of evolution. Pew Research Center's Religion \& Public Life Project. Retrieved February 19, 2020, from www.pewforum.org/2009/02/04/religious-differences-onthe-question-of-evolution

Pew. (2009b, January 30). A religious portrait of African-Americans. Pew Research Center's Religion \& Public Life Project. Retrieved February 19, 2020, from www.pewforum.org/2009/01/30/a-religious-portrait-of -african-americans

Pew. (2009c). Scientists and belief. Pew Research Center's Religion \& Public Life Project. Retrieved February 19, 2020, from www.pewforum .org/2009/11/05/scientists-and-belief

Pew. (2015). Religious landscape study. Pew Research Center's Religion \& Public Life Project. Retrieved February 19, 2020, from www.pewforum .org/religious-landscape-study

Pinheiro, J., Bates, D., DebRoy, S., Sarkar, D., \& Team, R. C. (2015). nlme: Linear and nonlinear mixed effects models. $R$ package version, 3(1), 111 Retrieved January 20, 2019, from https://rdrr.io/cran/nlme/

R Core Team. (2019). R: A language and environment for statistical computing, In R Foundation for Statistical Computing, Vienna, Austria. Retrieved January 15, 2020, from https://www.R-project.org
Rios, K., Cheng, Z. H., Totton, R. R., \& Shariff, A. F. (2015). Negative stereotypes cause Christians to underperform in and disidentify with science. Social Psychological and Personality Science. https://doi.org/ 10.1177/1948550615598378

Rissler, L. J., Duncan, S. I., \& Caruso, N. M. (2014). The relative importance of religion and education on university students' views of evolution in the Deep South and state science standards across the United States. Evolution: Education and Outreach, 7(1), 24. https://doi.org/10.1186/s12052014-0024-1

Robitzsch, A., Kiefer, T., \& Wu, M. (2018). TAM: Test analysis modules. R Package Version, 2, 9-35. Retrieved January 20, 2019, from https://rdrr.io/ cran/TAM/

Rodriguez, F., Rivas, M. J., Matsumura, L. H., Warschauer, M., \& Sato, B. K. (2018). How do students study in STEM courses? Findings from a lighttouch intervention and its relevance for underrepresented students. PLOS ONE, 13(7), e0200767. https://doi.org/10.1371/journal pone.0200767

Rutledge, M. L., \& Warden, M. A. (1999). The development and validation of the Measure of Acceptance of the Theory of Evolution Instrument. School Science and Mathematics, 99(1), 13-18. https://doi .org/10.1111/j.1949-8594.1999.tb17441.x

Salazar, E. S., Vaidyanathan, B., Ecklund, E. H., \& Garcia, A. (2019). Challenging evolution in public schools: Race, religion, and attitudes toward teaching creationism. Socius, 5, 2378023119870376. https://doi.org/10.1177/ 2378023119870376

Sbeglia, G. C., \& Nehm, R. H. (2018). Measuring evolution acceptance using the GAENE: Influences of gender, race, degree-plan, and instruction Evolution: Education and Outreach, 11(1), 18. https://doi.org/10.1186/ s12052-018-0091-9

Sbeglia, G. C., \& Nehm, R. H. (2019). Do you see what I-SEA? A Rasch analysis of the psychometric properties of the Inventory of Student Evolution Acceptance. Science Education, 103(2), 287-316. https://doi.org/10.1002/ sce. 21494

Smith, M. U., Snyder, S. W., \& Devereaux, R. S. (2016). The GAENE-Generalized Acceptance of Evolution Evaluation: Development of a new measure of evolution acceptance. Journal of Research in Science Teaching, 53(9), 1289-1315. https://doi.org/10.1002/tea.21328

Taylor, R. J., Chatters, L. M., Jayakody, R., \& Levin, J. S. (1996). Black and white differences in religious participation: A multisample comparison. Journal for the Scientific Study of Religion, 403-410.

Taylor, R. J., Chatters, L. M., \& Levin, J. (2003). Religion in the Lives of African Americans: Social, Psychological, and Health Perspectives. SAGE Publications.

Tingley, D., Yamamoto, T., Hirose, K., Keele, L., \& Imai, K. (2014). Mediation: $R$ package for causal mediation analysis, 59(5), 1-38. https://doi .org/10.18637/jss.v059.i05

Truong, J. M., Barnes, M. E., \& Brownell, S. E. (2018). Can six minutes of culturally competent evolution education reduce students' level of perceived conflict between evolution and religion? American Biology Teacher, 80(2), 106-115. https://doi.org/10.1525/abt.2018.80.2.106

Truth, S. (1851). Ain't I a woman? In The Proceedings of the Women's Rights Convention, held May 29, Ohio.

Wang, R., Hempton, B., Dugan, J. P., \& Komives, S. R. (2008). Cultural differences: Why do Asians avoid extreme responses? Survey Practice, 1(3), 2913. https://doi.org/10.29115/SP-2008-0011

Weisenfeld, J. (2015). Religion in African American history. Oxford Research Encyclopedia of American History. https://doi.org/10.1093/acrefore/9780199329175.013.24

Yosso, T. J. (2005). Whose culture has capital? A critical race theory discussion of community cultural wealth. Race Ethnicity and Education, 8(1), 69-91. https://doi.org/10.1080/1361332052000341006 